Extended Abstract

\title{
Finite-Rate Ablation Boundary Conditions \\ for Carbon-Phenolic Heat-Shield
}

by

Y.-K. Chen and F. S. Milos

NASA Ames Research Center, Moffett Field, CA 94035-1000

\begin{abstract}
A formulation of finite-rate ablation surface boundary conditions, including oxidation, nitridation, and sublimation of carbonaceous material with pyrolysis gas injection, has been developed based on surface species mass conservation. These surface boundary conditions are discretized and integrated with a Navier-Stokes solver. This numerical procedure can predict aerothermal heating, chemical species concentration, and carbonaceous material ablation rate over the heatshield surface of re-entry space vehicles. In this study, the gas-gas and gas-surface interactions are established for air flow over a carbon-phenolic heatshield. Two finite-rate gas-surface interaction models are considered in the present study. The first model is based on the work of Park, and the second model includes the kinetics suggested by Zhluktov and Abe. Nineteen gas phase chemical reactions and four gas-surface interactions are considered in the present model. There is a total of fourteen gas phase chemical species, including five species for air and nine species for ablation products. Three test cases are studied in this paper. The first case is a graphite test model in the arc-jet stream; the second is a light weight Phenolic Impregnated Carbon Ablator at the Stardust re-entry peak heating conditions, and the third is a fully dense carbon-phenolic heatshield at the peak heating point of a proposed Mars Sample Return Earth Entry Vehicle. Predictions based on both finite-rate gassurface interaction models are compared with those obtained using $B^{\prime}$ tables, which were created based on the chemical equilibrium assumption. Stagnation point convective heat fluxes predicted using Park's finite-rate model are far below those obtained from chemical equilibrium $B^{\prime}$ tables and Zhluktov's model. Recession predictions from Zhluktov's model are generally lower than those obtained from Park's model and chemical equilibrium $B^{\prime}$ tables. The effect of species mass diffusion on predicted ablation rate is also examined.
\end{abstract}

\section{Nomenclature}

$B^{\prime}=\dot{m} / \rho_{e} u_{e} C_{m}$, dimensionless mass blowing rate

$\mathrm{C}_{\mathrm{i}}=$ mass fraction for species $\mathrm{i}$

$(\mathrm{C}-\mathrm{i})=$ adatom $\mathrm{i}, \mathrm{O}$ or $\mathrm{N}$

$\mathrm{C}_{\mathrm{m}}=$ Stanton number for mass transfer

$\bar{D}=$ bifurcation diffusion coefficient, $\mathrm{m}^{2} / \mathrm{s}$

$D_{i}=$ diffusion coefficient for species $\mathrm{i}, \mathrm{m}^{2} / \mathrm{s}$

$E=$ total energy per unit volume, $\mathrm{J} / \mathrm{m}^{3}$

$\mathrm{F}=$ nonlinear equation defined in Eq (24), or $P_{0} / \sqrt{2 \pi m_{i} k T}$

$f_{i}=$ diffusion factor of species $i$ 
$\mathrm{h}=$ Plank's constant, J-s, or enthalpy, $\mathrm{J} / \mathrm{kg}$

$\mathrm{J}=$ mass diffusion flux, $\mathrm{kg} / \mathrm{m}^{2}-\mathrm{s}$

$\mathrm{K}_{\mathrm{i}}=$ equilibrium constant

$K_{t}=$ thermal conductivity of translation temperature, $\mathrm{W} / \mathrm{m}-\mathrm{K}$

$K_{v}=$ thermal conductivity of vibration temperature, $\mathrm{W} / \mathrm{m}-\mathrm{K}$

$k=$ Boltzmann constant, $\mathrm{J} / \mathrm{K}$

$\mathrm{k}_{\mathrm{f}}=$ forward reaction rate, defined in Eq (18)

$\mathrm{k}_{\mathrm{r}}=$ backward reaction rate, defined in $\mathrm{Eq}$ (18)

$\mathrm{m}_{\mathrm{i}}=$ mass of species $\mathrm{i}, \mathrm{kg}$

$\dot{m}=$ mass flux, $\mathrm{kg} / \mathrm{m}^{2}-\mathrm{s}$

$\mathrm{M}=$ molecular weight, $\mathrm{kg} /$ mole

$\mathrm{N}_{\mathrm{i}}=$ defined in $\mathrm{Eq}(12)$

$\mathrm{p}=$ pressure, $\mathrm{N} / \mathrm{m}^{2}$

$\mathrm{p}_{\mathrm{E}}=$ saturated vapor pressure, $\mathrm{N} / \mathrm{m}^{2}$

$\mathrm{q}_{\text {conv }}=$ convective heat flux, $\mathrm{W} / \mathrm{m}^{2}$

$q_{v}=$ heat flux due to species diffusion, $\mathrm{W} / \mathrm{m}^{2}$

$\mathrm{R}=$ universal gas constant, $\mathrm{J} / \mathrm{kmol}-\mathrm{K}$

$\mathrm{R}_{\mathrm{b}}=$ base radius, $\mathrm{m}$

$\mathrm{R}_{\mathrm{c}}=$ corner radius, $\mathrm{m}$

$\mathrm{R}_{\mathrm{n}}=$ nose radius, $\mathrm{m}$

$r_{i}=$ reaction rate, defined in Eq (14)

$\dot{S}=$ recession rate, $\mathrm{m} / \mathrm{s}$

$\mathrm{T}=$ temperature, $\mathrm{K}$

$\mathrm{t}=$ time, $\mathrm{s}$

$\mathrm{u}=$ fluid velocity, $\mathrm{m} / \mathrm{s}$

$v_{w}=$ mass injection velocity, $\mathrm{m} / \mathrm{s}$

$\mathrm{x}=$ Cartesian coordinate system, $\mathrm{m}$

$Z_{i}=$ bifurcation diffusion quantity of species $i$, defined in Eq. (4)

$\alpha=$ surface absorptance

$\beta=$ efficiency of gas-surface interaction

$\varepsilon \quad=$ surface emissivity

$\varepsilon_{\mathrm{i}}=$ factor in $\mathrm{i}^{\text {th }}$ heterogeneous reaction

$\Theta^{0}=$ free surface concentration

$\Theta_{\mathrm{i}}=$ surface coverage concentration of species $\mathrm{i}$

$\lambda=$ blowing reduction parameter in Eq.(12)

$\rho=$ density, $\mathrm{kg} / \mathrm{m}^{3}$

$\sigma=$ Stefan-Boltzmann constant, $\mathrm{W} / \mathrm{m}^{2}-\mathrm{K}^{4}$

$\tau=$ shear stress $\mathrm{N} / \mathrm{m}^{2}$

$\hat{\mu}_{i}=$ defined in Eq. (4)

$\eta=$ general body fitted coordinate system normal to surface, $m$

$v=$ species diffusion flux, $\mathrm{m} / \mathrm{s}$

$\bar{v}_{i}=\sqrt{k T_{w} / 2 \pi m_{i}}, \mathrm{~m} / \mathrm{s}$

$w=$ species source term in Eq.(8), $\mathrm{kg} / \mathrm{m}^{3}-\mathrm{s}$

$x=$ mole fraction 


$$
\begin{aligned}
& \nabla=\text { gradient } \mathrm{m}^{-1} \\
& \text { subscripts } \\
& \mathrm{c}=\text { char } \\
& \mathrm{E}=\text { chemical equilibrium } \\
& \mathrm{e}=\text { boundary-layer edge } \\
& \mathrm{g}=\text { pyrolysis gas } \\
& \mathrm{i}=\text { species or direction component } \\
& \mathrm{j}=\text { surface species, or direction component } \\
& \mathrm{s}=\text { gas species or stagnation point } \\
& \mathrm{v}=\text { virgin } \\
& \mathrm{w}=\text { wall }
\end{aligned}
$$

\section{Navier-Stokes Solver}

The Navier-Stokes solver, GIANTS, is used to estimate the hypersonic aerothermal heating distribution over a blunt body. The governing equations used in the code, as developed by Lee, ${ }^{1}$ may be characterized as representing a flowfield in thermochemical nonequilibrium. The GIANTS code solves the time-dependent conservation equations of mass, momentum, and energy for the chemical and thermal non-equilibrium flowfield. The species mass conservation equation is given $b y^{2}$

$$
\frac{\partial \rho_{s}}{\partial t}+\frac{\partial}{\partial x_{j}}\left(\rho_{s} u_{j}\right)=-\frac{\partial}{\partial x_{j}}\left(\rho_{s} v_{s j}\right)+w_{s} .
$$

the total momentum conservation is written as:

$$
\frac{\partial}{\partial t}\left(\rho u_{i}\right)+\frac{\partial}{\partial x_{j}}\left(\rho u_{i} u_{j}\right)=-\frac{\partial \tau_{i j}}{\partial x_{j}}
$$

and the total energy conservation is written as:

$$
\frac{\partial E}{\partial t}+\frac{\partial}{\partial x_{j}}\left((E+p) u_{j}\right)=-\frac{\partial}{\partial x_{j}}\left(q_{j}^{\prime}+q_{v j}\right)-\frac{\partial}{\partial x_{j}}\left(u_{i} \tau_{i j}\right)-\sum_{s=1}^{n} \frac{\partial}{\partial x_{j}} v_{s j} h_{s} .
$$

These equations are discretized using the implicit flux-split finite-volume method. The discretized equations may be solved by a block-tridiagonal matrix inversion using GaussSeidel line relaxation with alternating sweeps in the backward and forward directions. ${ }^{24}$ This technique has been shown to yield steady-state results efficiently. There is a total of fourteen gas phase species: $\mathrm{CO}_{2}, \mathrm{CO}, \mathrm{N}_{2}, \mathrm{O}_{2}, \mathrm{NO}, \mathrm{C}_{2}, \mathrm{C}_{3}, \mathrm{CN}, \mathrm{H}_{2}, \mathrm{HCN}, \mathrm{C}, \mathrm{N}, \mathrm{O}$ and $\mathrm{H}$. Five of the species are for air, and the rest are for ablation products. The gas phase chemical reactions implemented in the GIANTS code are from the work of Park. ${ }^{5}$ The total number of reactions is nineteen, including nine dissociation reactions and ten exchange reactions, as follows:

Dissociation reactions 
(1) $\mathrm{CO}_{2}+\mathrm{M} \leftrightarrow \mathrm{CO}+\mathrm{O}+\mathrm{M}$

(2) $\mathrm{CO}+\mathrm{M} \leftrightarrow \mathrm{C}+\mathrm{O}+\mathrm{M}$

(3) $\mathrm{N}_{2}+\mathrm{M} \leftrightarrow \mathrm{N}+\mathrm{N}+\mathrm{M}$

(4) $\mathrm{O}_{2}+\mathrm{M} \leftrightarrow \mathrm{O}+\mathrm{O}+\mathrm{M}$

(5) $\mathrm{NO}+\mathrm{M} \leftrightarrow \mathrm{N}+\mathrm{O}+\mathrm{M}$

(6) $\mathrm{C}_{2}+\mathrm{M} \leftrightarrow \mathrm{C}+\mathrm{C}+\mathrm{M}$

(7) $\mathrm{C}_{3}+\mathrm{M} \leftrightarrow \mathrm{C}_{2}+\mathrm{C}+\mathrm{M}$

(8) $\mathrm{CN}+\mathrm{M} \leftrightarrow \mathrm{C}+\mathrm{N}+\mathrm{M}$

(9) $\mathrm{H}_{2}+\mathrm{M} \leftrightarrow \mathrm{H}+\mathrm{H}+\mathrm{M}$

Exchange reactions

(10) $\mathrm{NO}+\mathrm{O} \leftrightarrow \mathrm{N}+\mathrm{O}_{2}$

(11) $\mathrm{N}_{2}+\mathrm{O} \leftrightarrow \mathrm{NO}+\mathrm{N}$

(12) $\mathrm{CO}+\mathrm{O} \leftrightarrow \mathrm{O}_{2}+\mathrm{C}$

(13) $\mathrm{CO}_{2}+\mathrm{O} \leftrightarrow \mathrm{O}_{2}+\mathrm{CO}$

(14) $\mathrm{CO}+\mathrm{C} \leftrightarrow \mathrm{C}_{2}+\mathrm{O}$

(15) $\mathrm{CO}+\mathrm{N} \leftrightarrow \mathrm{CN}+\mathrm{O}$

(16) $\mathrm{N}_{2}+\mathrm{C} \leftrightarrow \mathrm{CN}+\mathrm{N}$

(17) $\mathrm{CN}+\mathrm{O} \leftrightarrow \mathrm{NO}+\mathrm{C}$

(18) $\mathrm{CN}+\mathrm{C} \leftrightarrow \mathrm{C}_{2}+\mathrm{N}$

(19) $\mathrm{HCN}+\mathrm{H} \leftrightarrow \mathrm{CN}+\mathrm{H}_{2}$

The mass diffusion models implemented in the GIANTS code include the constant Lewis number (Le), the constant Schmidt number (Sc), and the Bifurcation approximation. For the bifurcation model, the species mass diffusion rate is defined as ${ }^{6}$ :

$$
J_{i}=-\rho \bar{D} \frac{\hat{\mu}_{1}}{\hat{\mu}_{2}} \nabla Z_{i}
$$

where

$$
Z_{i}=\frac{C_{i}}{f_{i} \hat{\mu}_{1}}, \quad \hat{\mu}_{1}=\sum \frac{C_{i}}{f_{i}}, \quad \hat{\mu}_{2}=M \sum \frac{C_{i} f_{i}}{M_{i}} .
$$

The total convective heat flux to the surface is given as:

$$
q_{\text {conv }}=K_{t} \nabla T_{t}+K_{v} \nabla T_{v}+\sum h_{i} \rho D_{i} \nabla \chi_{i} .
$$

\section{Gas-Surface Interactions} study.

Two finite-rate, gas-surface interaction models are considered in the present

\section{Park Model}

Three kinds of gas-surface interactions for the carbonaceous ablating surface are considered. The gas-solid reactions include oxidation, Eqs.(6)-(7), and nitridation, Eq.(8). Following the assumption made in Park's work, ${ }^{7-9}$ the surface catalysis reactions are assumed to be negligibly small for both oxygen atom and nitrogen atom 
recombination at the ablating surface. The sublimation of carbon produces primarily $\mathrm{C}_{3}$ by Eq.(9). The species $C_{5}$ and $C_{7}$ are not included, because the entry conditions studied in this work have a stagnation point pressure of less than $1 \mathrm{~atm}$. Thus, the carbon mass blowing rates due to gas-surface interaction are:

$$
\begin{array}{ll}
\dot{m}_{1}=\rho C_{O} \bar{v}_{O} \beta_{O} \frac{M_{C}}{M_{O}} & \left(O+C_{(s)} \rightarrow C O\right) \\
\dot{m}_{2}=2 \rho C_{O_{2}} \bar{v}_{O_{2}} \beta_{O_{2}} \frac{M_{C}}{M_{O_{2}}} & \left(O_{2}+2 C_{(s)} \rightarrow 2 C O\right) \\
\dot{m}_{3}=\rho C_{N} \bar{v}_{N} \beta_{N} \frac{M_{C}}{M_{N}} & \left(N+C_{(s)} \rightarrow C N\right) \\
\dot{m}_{4}=\rho\left(C_{C_{3}, E}-C_{C_{3}}\right) \bar{v}_{C_{3}} \beta_{C_{3}} & \left(3 C_{(s)} \rightarrow C_{3}\right) \\
\dot{m}_{c}=\dot{m}_{1}+\dot{m}_{2}+\dot{m}_{3}+\dot{m}_{4}=\rho_{(s)} \dot{S} &
\end{array}
$$

Here, $\bar{v}_{i}$ is defined as $\sqrt{k T_{w} / 2 \pi m_{i}}$. The total carbon mass blowing rate, $\dot{m}_{c}$, and the carbon surface recession rate, $\dot{S}$, can be computed from the total carbon mass loss. $\beta$ is the efficiency of each surface reaction. ${ }^{9} \beta_{\mathrm{O}}$ is given as $0.63 \exp \left(-1160 / T_{W}\right) \cdot \beta_{\mathrm{N}}$ and $\beta_{\mathrm{O} 2}$ are assumed to be 0.3 and 0.5 , respectively, and $\beta_{C 3}$ is set to 1 . The saturated carbon vapor pressure $\left(\mathrm{P}_{E}\right)$ for carbon-phenolic is expressed as ${ }^{9}$ :

$$
p_{E}=6.27 \times 10^{15} e^{\left(-\frac{90908}{T_{w}}\right)}
$$

and for carbon as:

$$
p_{E}=5.19 \times 10^{15} e^{\left(-\frac{90845}{T_{w}}\right)} .
$$

Species mass conservation at the surface is written as:

$$
-\rho D_{i} \nabla \chi_{i}+\rho v_{w} C_{i}=\hat{N}_{i}+\dot{m}_{g} C_{i, g}
$$

The first term on the left-hand side is mass transfer through diffusion, and the second term is mass transfer due to convection. On the right-hand side are the source terms due to gas-surface interaction and pyrolysis gas injection. For graphite or pure carbon heatshield materials, the pyrolysis gas injection rate, $\dot{m}_{g}$, is zero. Here the source term, $\hat{N}_{i}$, is defined as: 


$$
\begin{aligned}
& \hat{N}_{C O}=\dot{m}_{1} \frac{M_{C O}}{M_{C}}+\dot{m}_{2} \frac{M_{C O}}{M_{C}}, \hat{N}_{C N}=\dot{m}_{3} \frac{M_{C N}}{M_{C}}, \hat{N}_{C_{3}}=\dot{m}_{4}, \\
& \hat{N}_{N}=-\dot{m}_{3} \frac{M_{N}}{M_{C}}, \hat{N}_{O}=-\dot{m}_{1} \frac{M_{O}}{M_{C}}, \hat{N}_{O_{2}}=-\dot{m}_{2} \frac{M_{O_{2}}}{2 M_{C}},
\end{aligned}
$$

and $\hat{N}_{i}=0 \quad$ for $i=\mathrm{CO}_{2}, \mathrm{~N}_{2}, \mathrm{NO}, \mathrm{C}_{2}$, and $\mathrm{C}$.

Based on global mass balance, the following equation for total mass blowing is expressed:

$$
\rho v_{w}=\dot{m}_{c}+\dot{m}_{g}
$$

\section{Zhluktov Model}

The following surface-kinetic model is suggested in the work of Zhluktov and Abe ${ }^{10}$ :

1. $\mathrm{O}+(\mathrm{C})<=>(\mathrm{C}-\mathrm{O})$

2. $\mathrm{O}_{2}+2(\mathrm{C})<==>2(\mathrm{C}-\mathrm{O})$

3. $\mathrm{O}_{2}+(\mathrm{C}) \Leftrightarrow(\mathrm{C}-\mathrm{O})+\mathrm{O}$

4. $\mathrm{CO}_{2}+(\mathrm{C}) \Longleftrightarrow(\mathrm{C}-\mathrm{O})+\mathrm{CO}$

5. $(\mathrm{C}-\mathrm{O}) \Leftrightarrow \mathrm{CO}+(\mathrm{C})$

6. $\mathrm{O}+(\mathrm{C}-\mathrm{O}) \Leftrightarrow \mathrm{CO}_{2}+(\mathrm{C})$

7. $2(\mathrm{C}-\mathrm{O}) \Leftrightarrow=\mathrm{CO}_{2}+2(\mathrm{C})$

8. (C) $\Leftrightarrow \mathrm{C}+(\mathrm{C})$

9. $2(\mathrm{C}) \Longleftrightarrow \mathrm{C}_{2}+2(\mathrm{C})$

10. $3(\mathrm{C}) \Leftrightarrow=\mathrm{C}_{3}+3(\mathrm{C})$

11. $\mathrm{N}+(\mathrm{C}) \Longleftrightarrow(\mathrm{C}-\mathrm{N})$

12. (C-N) $+\mathrm{N}<==>\mathrm{N}_{2}+(\mathrm{C})$

The corresponding reaction rates are as follows:

$$
\begin{aligned}
& r_{1}=k_{f 1}\left(p \chi_{O} \Theta^{0}-\Theta_{O} / K_{1}\right) \\
& r_{2}=k_{r 2}\left(K_{2} p \chi_{O_{2}}\left(\Theta^{0}\right)^{2}-\left(\Theta_{O}\right)^{2}\right) \\
& r_{3}=k_{f 3}\left(p \chi_{O_{2}} \Theta^{0}-p \chi_{O} \Theta_{O} / K_{3}\right) \\
& r_{4}=k_{f 4}\left(p \chi_{C O_{2}} \Theta^{0}-p \chi_{C O} \Theta_{O} / K_{4}\right) \\
& r_{5}=k_{f 5}\left(\Theta_{O}-p \chi_{C O} \Theta^{0} / K_{5}\right) \\
& r_{6}=k_{f 6}\left(p \chi_{O} \Theta_{O}-p \chi_{C O_{2}} \Theta^{0} / K_{6}\right)
\end{aligned}
$$




$$
\begin{aligned}
& r_{7}=k_{f 7}\left(\left(\Theta_{O}\right)^{2}-p \chi_{C O_{2}}\left(\Theta^{0}\right)^{2} / K_{7}\right) \\
& r_{8}=k_{r 8} \Theta^{0}\left(K_{8}-p \chi_{C}\right) \\
& r_{9}=k_{r 9}\left(\Theta^{0}\right)^{2}\left(K_{9}-p \chi_{C_{2}}\right) \\
& r_{10}=k_{r 10}\left(\Theta^{0}\right)^{3}\left(K_{10}-p \chi_{C_{3}}\right) \\
& r_{11}=k_{f 11}\left(p \chi_{N} \Theta^{0}-\Theta_{N} / K_{11}\right) \\
& r_{12}=k_{r 12}\left(K_{12} p \chi_{N} \Theta_{N}-p \chi_{N_{2}} \Theta^{0}\right)
\end{aligned}
$$

It is assumed that two possibilities exist for $\mathrm{K}_{1}$ and $\mathrm{K}_{11}$. The first is mobile adsorption:

$$
\frac{1}{K_{i}}=B \frac{k T}{P_{0}}\left(\frac{2 \pi m_{i} k T}{h^{2}}\right)^{1 / 2} e^{-T_{d_{i}} / T}, a t m
$$

and the second is immobile adsorption:

$$
\frac{1}{K_{i}}=\frac{k T}{P_{0}}\left(\frac{2 \pi m_{i} k T}{h^{2}}\right)^{3 / 2} e^{-T_{d_{i}} / T}, a t m
$$

where $\mathrm{i}=1$ or $11, \mathrm{P}_{0}=1.01325 \times 10^{5} \mathrm{~Pa}$, and $\mathrm{B}=3.5 \times 10^{19} \mathrm{~m}^{-2}$.

The equilibrium constants $\mathrm{K}_{1}$ to $\mathrm{K}_{12}$ are not independent. They are related via gas phase equilibrium constants of corresponding dissociation processes:

$$
\begin{aligned}
& K_{2}=\left(K_{1}\right)^{2} K_{O_{2}} \\
& K_{3}=K_{1} K_{O_{2}} \\
& K_{4}=K_{1} K_{C O_{2}} \\
& K_{5}=K_{8} /\left(K_{1} K_{C O}\right) \\
& K_{6}=K_{8} /\left(K_{1} K_{C O} K_{C O_{2}}\right) \\
& K_{7}=K_{8} /\left(\left(K_{1}\right)^{2} K_{C O} K_{C O_{2}}\right) \\
& K_{9}=\left(K_{8}\right)^{2} / K_{C_{2}} \\
& K_{10}=\left(K_{8}\right)^{3} /\left(K_{C_{2}} K_{C_{3}}\right) \\
& K_{12}=1 /\left(K_{11} K_{N_{2}}\right)
\end{aligned}
$$

The recommended expressions for necessary forward or backward reaction rate constants as follows: 


$$
\begin{aligned}
& k_{f 1}=\varepsilon_{1} F_{O} \\
& k_{r 2}=\varepsilon_{2} B\left(\frac{k T}{h}\right) e^{-T_{a 2} / T} \\
& k_{f 3}=\varepsilon_{3} F_{O_{2}} e^{-T_{a 3} / T} \\
& k_{f 4}=\varepsilon_{4} F_{C O_{2}} \\
& k_{f 5}=\varepsilon_{5} B\left(\frac{k T}{h}\right) e^{-T_{a 5} / T} \\
& k_{f 6}=\varepsilon_{6} F_{O} e^{-T_{a 6} / T} \\
& k_{f 7}=\varepsilon_{7} B\left(\frac{k T}{h}\right) e^{-T_{a 7} / T} \\
& k_{r 8}=\varepsilon_{8} F_{C} \\
& k_{r 9}=\varepsilon_{9} F_{C_{2}} \\
& k_{r 10}=\varepsilon_{10} F_{C_{3}} \\
& k_{f 11}=\varepsilon_{11} F_{N} \\
& k_{r 12}=\varepsilon_{12} F_{N_{2}} e^{-T_{a 12} / T}
\end{aligned}
$$

where

$$
\begin{aligned}
& F_{i}=P_{0} / \sqrt{2 \pi m_{i} k T} \\
& \varepsilon_{1}=1, \varepsilon_{2}=0.0008, \varepsilon_{3}=1, \varepsilon_{4}=0.9 \\
& \varepsilon_{5}=0.1, \varepsilon_{6}=0.8, \varepsilon_{7}=1, \varepsilon_{8}=0.24 \\
& \varepsilon_{9}=0.5, \varepsilon_{10}=0.023, \varepsilon_{11}=1, \varepsilon_{12}=1 \\
& T_{d 1}=45,000 \\
& T_{d 11}=36,600 \\
& T_{a 2}=2 T_{d 1}-T_{D O_{2}} \\
& T_{a 3}=T_{D O_{2}}-T_{d 1} \\
& T_{a 12}=T_{D N_{2}}-T_{d 11} \\
& T_{a 5}=40,000,34,000, \text { or } 27,000 \\
& T_{a 6}=2000 \text { or } 1000 \\
& T_{a 7}=40,000,34,000, \text { or } 13,700
\end{aligned}
$$

The rates of species production on the surface are: 


$$
\begin{aligned}
& \dot{m}_{O}=\left(-r_{1}+r_{3}-r_{6}\right) M_{O} \\
& \dot{m}_{C O}=\left(r_{4}+r_{5}\right) M_{C O} \\
& \dot{m}_{C O_{2}}=\left(-r_{4}+r_{6}+r_{7}\right) M_{C O_{2}} \\
& \dot{m}_{C}=r_{8} M_{C} \\
& \dot{m}_{C_{2}}=r_{9} M_{C_{2}} \\
& \dot{m}_{C_{3}}=r_{10} M_{C_{3}} \\
& \dot{m}_{N O}=0 \\
& \dot{m}_{C N}=0 \\
& \dot{m}_{N}=\left(-r_{11}-r_{12}\right) M_{N} \\
& \dot{m}_{O_{2}}=\left(-r_{2}-r_{3}\right) M_{O_{2}} \\
& \dot{m}_{N_{2}}=r_{12} M_{N_{2}}
\end{aligned}
$$

For a stationary regime we have:

$$
\begin{aligned}
& \dot{m}_{(C-O)}=\left(r_{1}+2 r_{2}+r_{3}+r_{4}-r_{5}-r_{6}-2 r_{7}\right) M_{O}=0 \\
& \dot{m}_{(C-N)}=\left(r_{11}-r_{12}\right) M_{N}=0 .
\end{aligned}
$$

Using these expressions, the total surface mass blowing rate is,

$$
\dot{m}=\sum \dot{m}_{i}=M_{C}\left(r_{5}+r_{6}+r_{7}+r_{8}+2 r_{9}+3 r_{10}\right) .
$$

The sum of surface coverage concentrations is equal to 1 ; that is,

$$
\Theta_{O}+\Theta_{N}+\Theta^{0}=1
$$

Species conservation at the surface is written as:

$$
-\rho D_{i} \nabla \chi_{i}+\rho v_{w} C_{i}=\dot{m}_{i}+\dot{m}_{g} C_{i, g}
$$

The total number of unknowns is 13 , including:

$$
\left[\chi O, \chi_{2}, \chi_{N}, \chi_{N_{2}}, \chi_{C}, \chi_{C_{2}}, \chi_{C_{3}}, \chi_{C N}, \chi C O, \chi_{C O}, \Theta_{O}, \Theta_{N}, \Theta^{0}\right]
$$

The nonlinear equations can be solved through iterations by the following equation,

$$
\Delta Z_{j}=-\left(\frac{\partial F_{i}}{\partial Z_{j}}\right)^{-1} F_{i}
$$


The surface temperature $\left(\mathrm{T}_{\mathrm{w}}\right)$, pyrolysis gas injection rate $\left(\dot{m}_{g}\right)$, and species concentrations of pyrolysis gas $\left(C_{i, g}\right)$ must be specified. The pyrolysis gas is assumed to be at chemical equilibrium before being injected into the main stream. The surface temperature and pyrolysis gas injection rate are obtained from the material response code through iterations. Species concentrations, $C_{i, w}$, and velocity, $v_{w}$, at each surface grid point are updated in each sweep (both backward and forward) until a steady-state flow solution is reached. Thus, the carbon mass injection and surface recession rates can be obtained as part of the flow solution.

\section{Results and Discussion}

The general carbon-phenolic ablation model without pyrolysis gas injection can be used to simulate graphite ablation. In the first test case, the interaction between a graphite model and a typical arc-jet stream conducted in the Interactive Heating Facilities at NASA Ames Research Center is studied. The stream total enthalpy is estimated to be approximately $27 \mathrm{MJ} / \mathrm{Kg}$, and the measured stagnation point pressure is $0.75 \mathrm{~atm}$. The free stream velocity is $5354 \mathrm{~m} / \mathrm{s}$, the density is $0.003 \mathrm{~kg} / \mathrm{m}^{3}$, and the temperature is 1428 $\mathrm{K}$. The free stream species mass concentrations are $\mathrm{C}_{\mathrm{O} 2}=0.0, \mathrm{C}_{\mathrm{N} 2}=0.6169, \mathrm{C}_{\mathrm{NO}}=$ $0.0046, \mathrm{C}_{\mathrm{N}}=0.1212$, and $\mathrm{C}_{\mathrm{O}}=0.2573$. In this arc-jet stream, oxygen is fully dissociated and nitrogen is partially dissociated. The graphite model is a $10^{\circ}$ half angle sphere-cone with nose radius $(\mathrm{Rn})$ of $1.905 \mathrm{~cm}$. The geometry and computational grid for this test model are shown in Fig. 1. The surface temperature obtained from a solid-fluid coupled chemical equilibrium ablating surface computation is used as the temperature boundary condition in the finite-rate ablation surface calculation (Fig. 2). This is to study the surface reaction rates of Park and Zhluktov under the same given surface conditions without a fully coupled computation. Additionally, the predictions based on the steadystate ablation surface conditions will also be presented and compared in the final paper. The predicted carbon mass blowing rate distributions over the model surface are shown in Fig. 3. The comparison of predicted surface heat fluxes is presented in Fig. 4.

The second test case simulates the flow over a Phenolic Impregnated Carbon Ablator (PICA) heatshield at estimated Stardust re-entry peak heating conditions. PICA has density of about $240 \mathrm{~kg} / \mathrm{m}^{3}$, which is much lower than fully dense carbon-phenolic, which has a density of $1440 \mathrm{~kg} / \mathrm{m}^{3}$. The aeroshell of the Stardust re-entry vehicle is a $60^{\circ}$ half angle spherical cone with the nose radius $(\mathrm{Rn})$ of $0.2286 \mathrm{~m}$, base radius $(\mathrm{Rb})$ of $0.4064 \mathrm{~m}$, and corner radius $(\mathrm{Rc})$ of $0.02 \mathrm{~m}$. The free stream velocity is $11137 \mathrm{~m} / \mathrm{s}$, the density is $0.000234 \mathrm{~kg} / \mathrm{m}^{3}$, and the temperature is $238 \mathrm{~K}$. The geometry and computational grid for the Stardust aeroshell are shown in Fig. 5. The surface temperature and pyrolysis gas injection rate distributions ${ }^{11}$ used as part of the boundary conditions are shown in Fig. 6. The predicted total mass blowing rates, including char and pyrolysis gas, are presented in Fig. 7. Figure 8 shows the comparison of predicted

convective heat fluxes. The stagnation streamline solution computed in Park's study ${ }^{8}$ is approximately $5 \%$ higher than the current finite-rate prediction.

The third test case predicts the flow over a fully dense carbon-phenolic heatshield at peak heating point of the proposed MSR EEV trajectory. The forebody heatshield is a 
$60^{\circ}$ half angle spherical cone with a nose radius $(\mathrm{Rn})$ of $0.352 \mathrm{~m}$, a base radius $(\mathrm{Rb})$ of $0.45 \mathrm{~m}$, and a corner radius $(\mathrm{Rc})$ of $0.02 \mathrm{~m}$. The free stream velocity is $10100 \mathrm{~m} / \mathrm{s}$, the density is $0.0006634 \mathrm{~kg} / \mathrm{m}^{3}$, and the temperature is $255 \mathrm{~K}$. The peak heating stream velocity and the geometry of the MSR EEV aeroshell are similar to those of Stardust. MSR EEV has a larger $\mathrm{Rb}$ and $\mathrm{Rn}$, and the stream density is almost 3 times as high as Stardust. The geometry and computational grid for this test case are shown in Fig. 9. The temperature and pyrolysis gas injection rate distributions used in this test case are shown in Fig. 10. The predicted total mass blowing rates (char and pyrolysis gas) are presented in Fig. 11. In this test case, a large portion of surface mass blowing comes from the pyrolysis gas injection, which is approximately $0.09 \mathrm{~kg} / \mathrm{m}^{2}-\mathrm{s}$. The carbon char mass blowing rate is smaller than the pyrolysis gas injection rate over the entire heat-shield surface. Figure 12 shows the predicted surface heat fluxes. The calculated heating distribution using chemical equilibrium surface is quite different from using finite-rate surface.

Further details of the predicted flow fields and the effect of the mass diffusion model on the ablation rate will be included in the final paper.

\section{References}

${ }^{1}$ Lee, J.H.,"Basic Governing Equations for the Flight Regimes of Aeroassisted Orbital Transfer Vehicles", Thermal Design of Aeroassisted Orbital Transfer Vehicles, edited by H.F. Nelson, Vol. 96, Progress in Astronautics and Aeronautics, AIAA, New York, 1985, pp. 3-53.

${ }^{2}$ Candler, G.V., "The Computation of Hypersonic Ionized Flows in Chemical and Thermal Nonequilibrium," AIAA Paper 88-0511, January 1988.

${ }^{3}$ MacCormack, R.W., "Current Status of Numerical Solutions of the Navier-Stokes Equation," AIAA Paper 85-0032, Jan 1985.

${ }^{4}$ Candler, G.V., and MacCormack, R. W., "Hypersonic Flow Past 3-D Configuration," AIAA Paper 87-0480, June 1987.

${ }^{5}$ Park, C., "Review of Chemical Kinetic Problems of Future NASA Missions, I: Earth Entries," Journal of Thermophysics and Heat Transfer Vol. 7, Number 3, July 1993, pp. 385-398.

${ }^{6}$ Anon., User's Manual: Aerotherm Chemical Equilibrium Computer Program, Acurex Corporation, Aerotherm Division, Mountain View, California, Aug. 1981.

${ }^{7}$ Park, C., and Ahn, H.K., "Stagnation-Point Heat Transfer for Pioneer-Venus Probes," Journal of Thermophysics and Heat Transfer, Vol. 13, No. 1, January-March 1999, pp. 33-41.

${ }^{8}$ Park, C., "Calculation of Stagnation-Point Heating Rates Associated with Stardust Vehicle", Proposed NASA Technical Memorandum, 2002.

${ }^{9}$ Park, C., "Stagnation-Point Ablation of Carbonaceous Flat Disks-Part I: Theory", AIAA Journal, Vol. 21, No. 11, November 1983, pp. 1588-1594

${ }^{10}$ Zhluktov, S.V. and Abe, T., "Viscous Shock-Layer Simulation of Airflow past Ablating Blunt Body with Carbon Surface," Journal of Thermophysics and Heat Transfer, Vol. 13, No. 1, January-March 1999, pp. 50-59.

${ }^{11}$ Olynick, D.R., Chen, Y-K, and Tauber, M.E., "Aerothermodynamics of the Stardust Sample Return Capsule", J. of Spacecraft and Rockets, Vol. 36, No. 3, May-June 1999, pp. 442-462. 


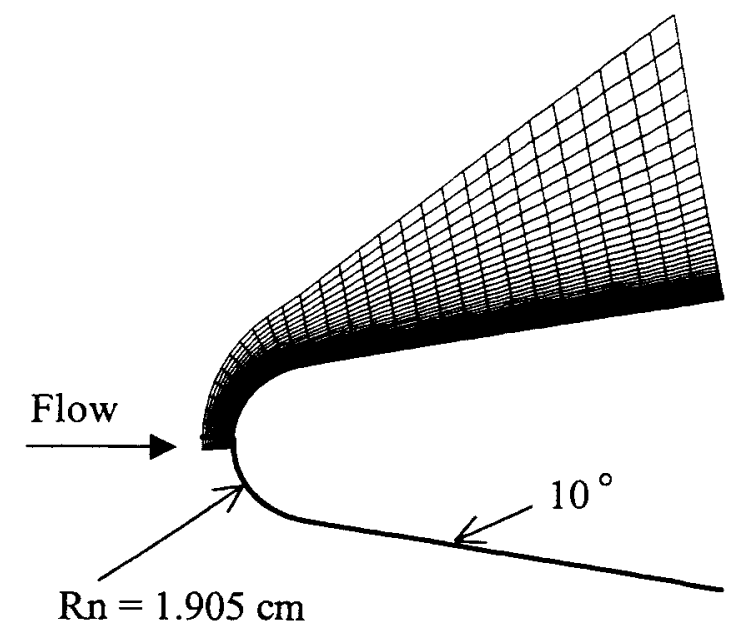

Figure 1: Geometry and computational grid for case 1

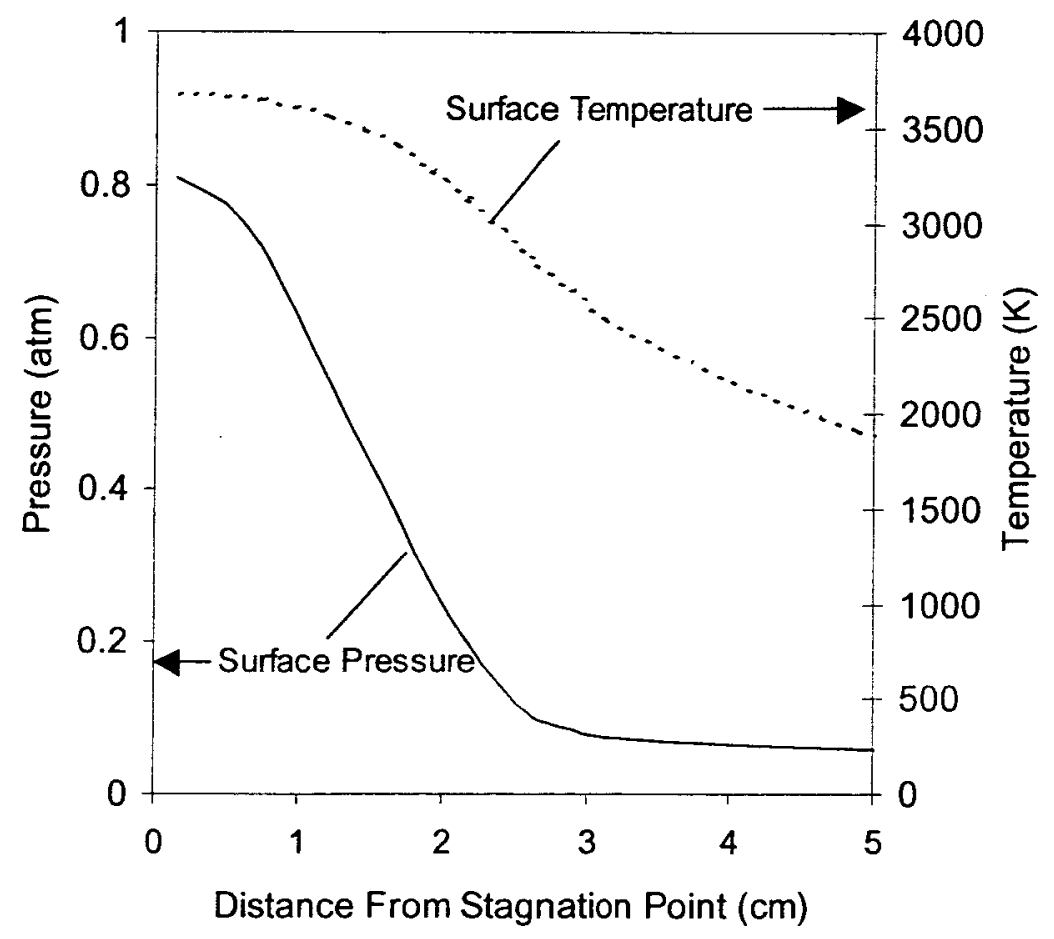

Figure 2: Surface temperature and pressure boundary conditions used for case 1 simulation 


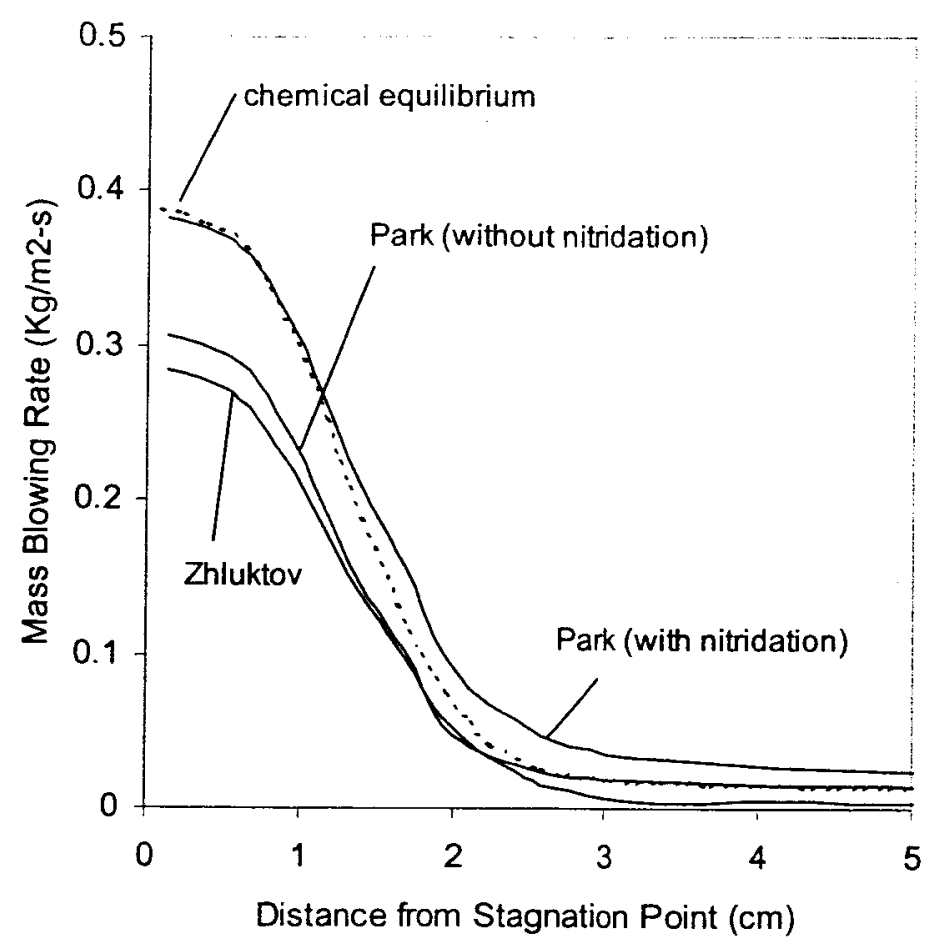

Figure 3: Predicted carbon mass blowing rate distributions for case 1

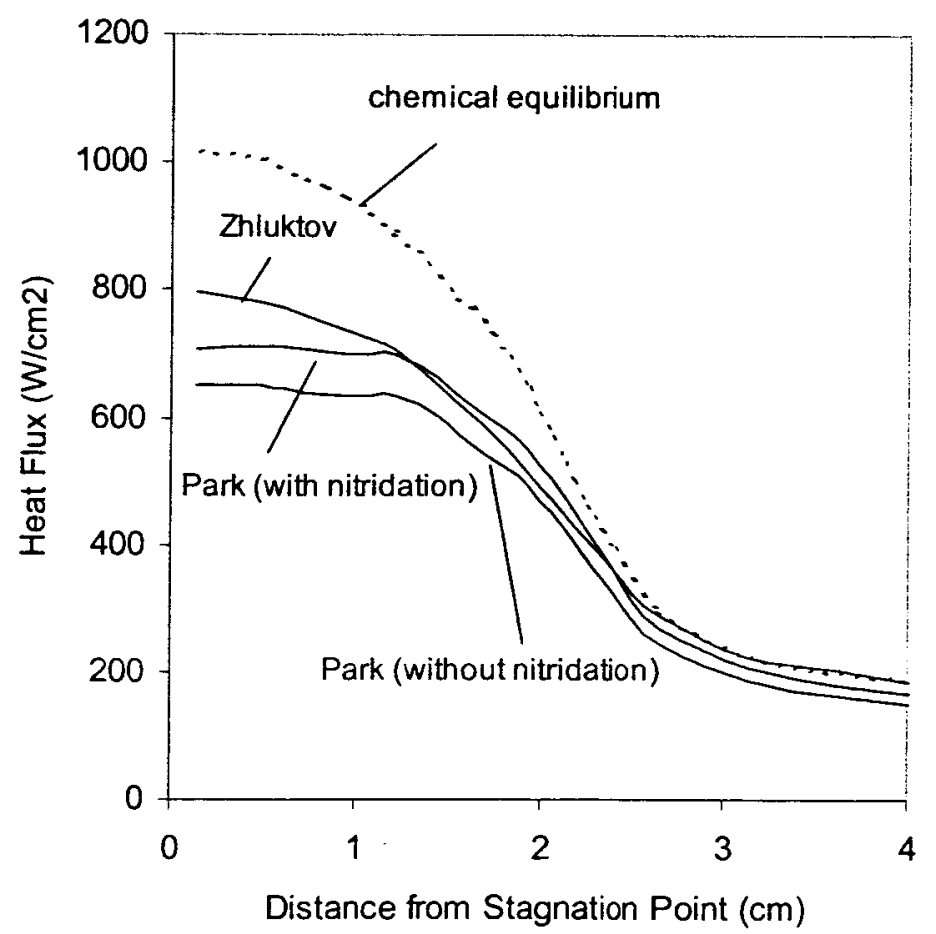

Figure 4: Comparison of surface convective heat flux predictions for case 1 


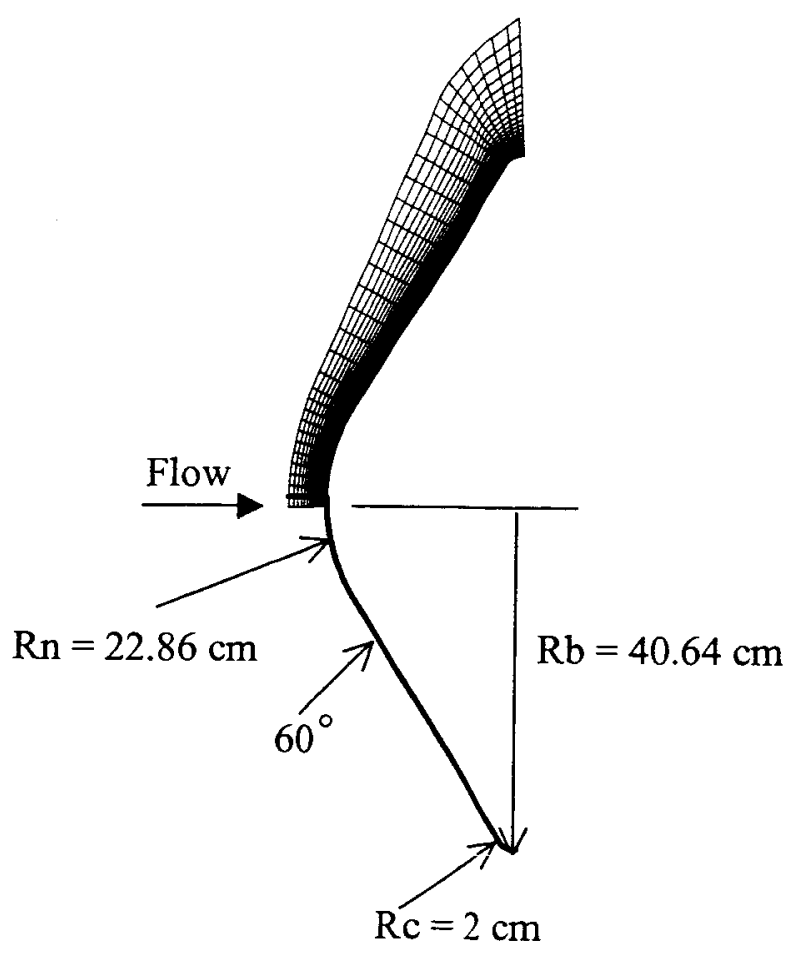

Figure 5: Geometry and computational grid for case 2

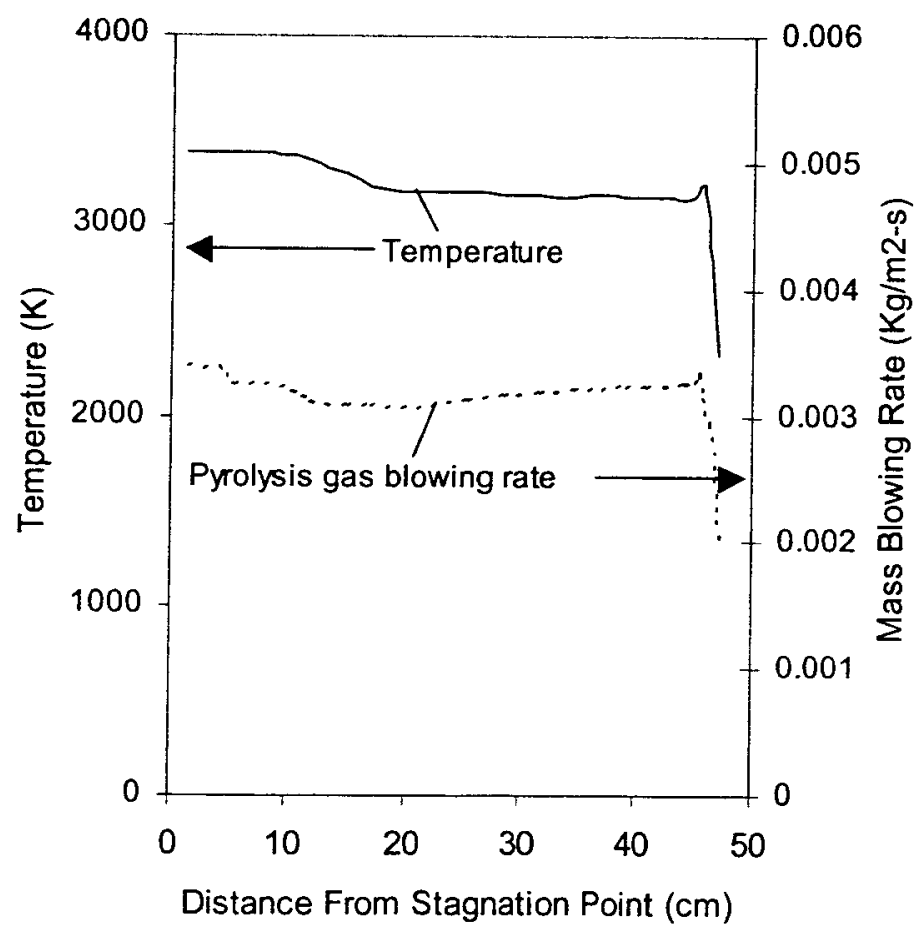

Figure 6: Surtace temperature and pyrolysis gas

blowing rate distributions used in case 2 simulation 


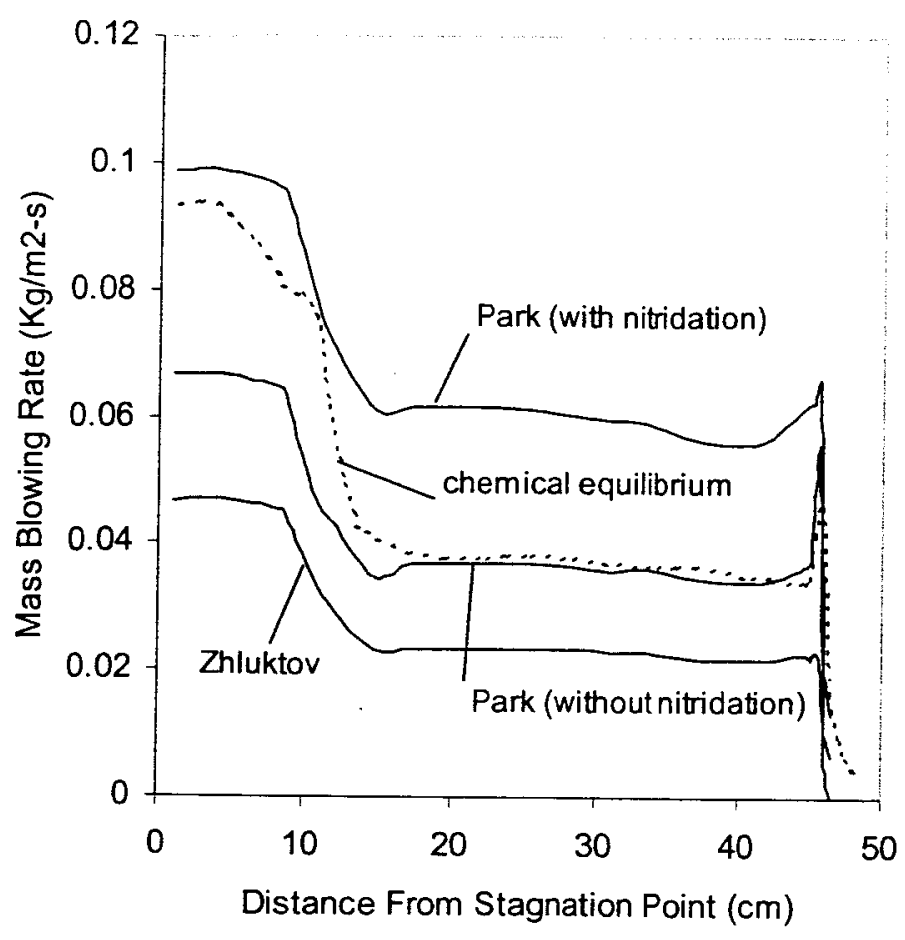

Figure 7: Predicted total mass blowing rate distributions for case 2

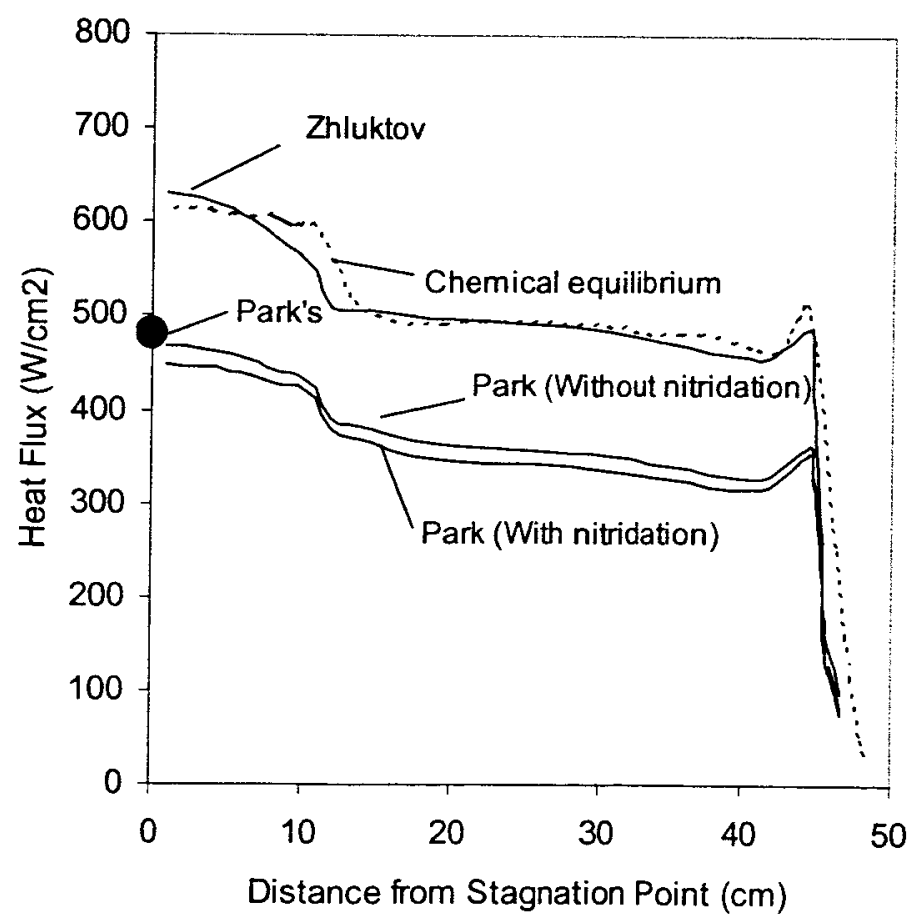

Figure 8: Comparison of convective heat flux predictions for case 2 


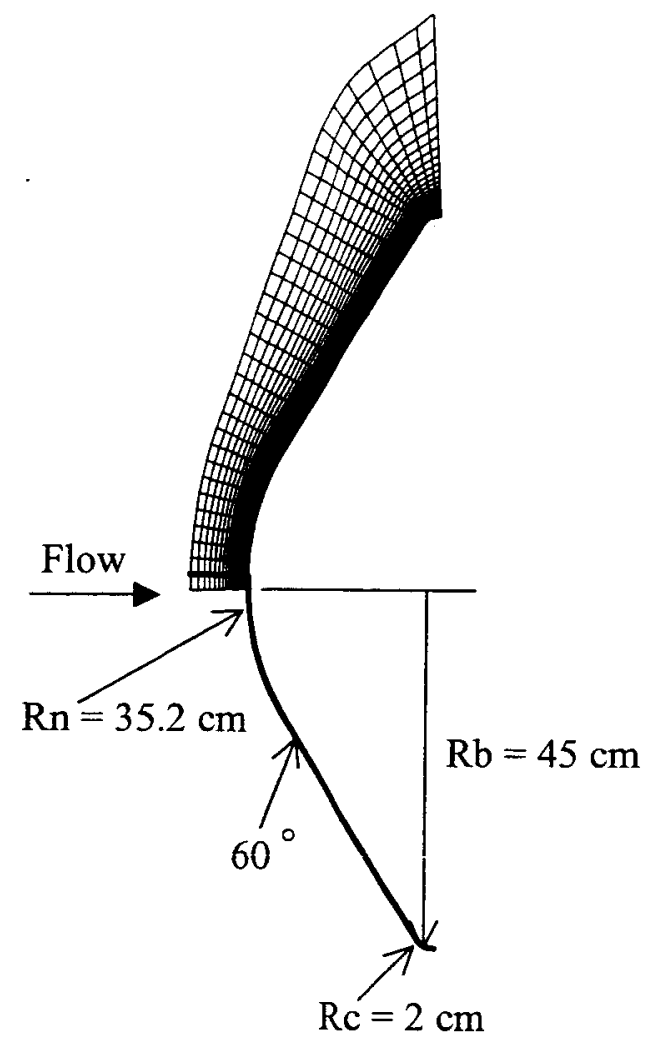

Figure 9: Geometry and computational grid for case 3

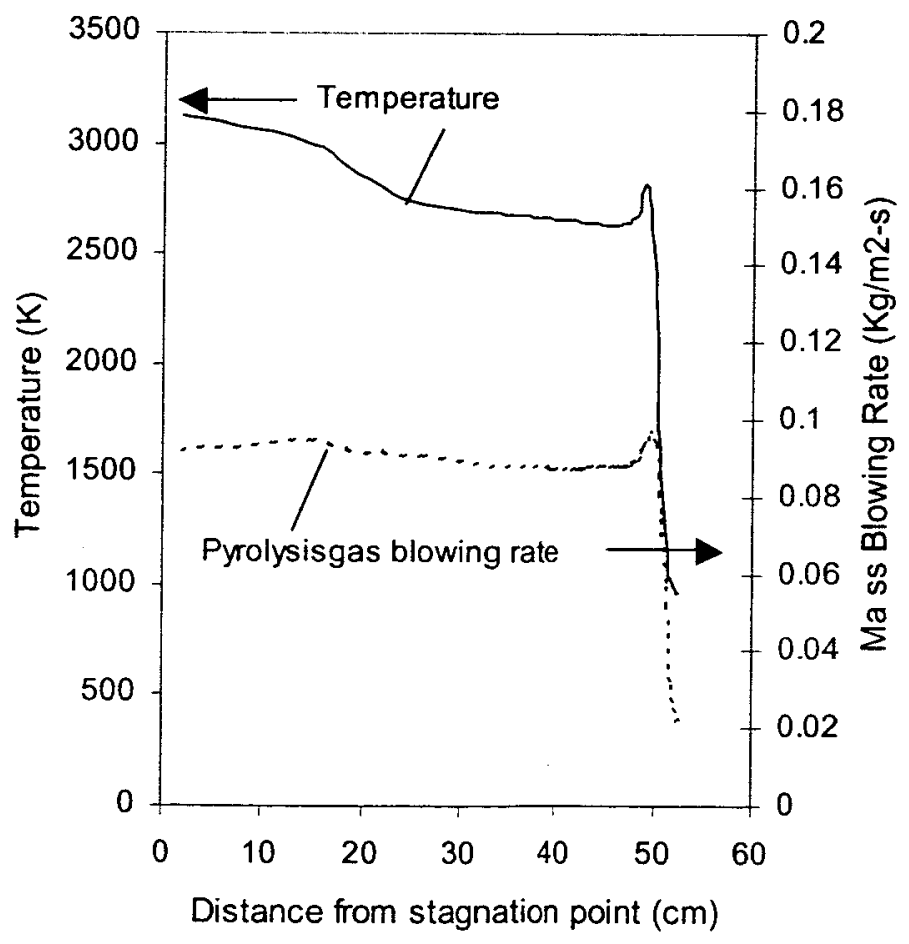

Figure 10: Surface temperature and pyrolysis gas injection rate distributions used in case 3 simulation. 


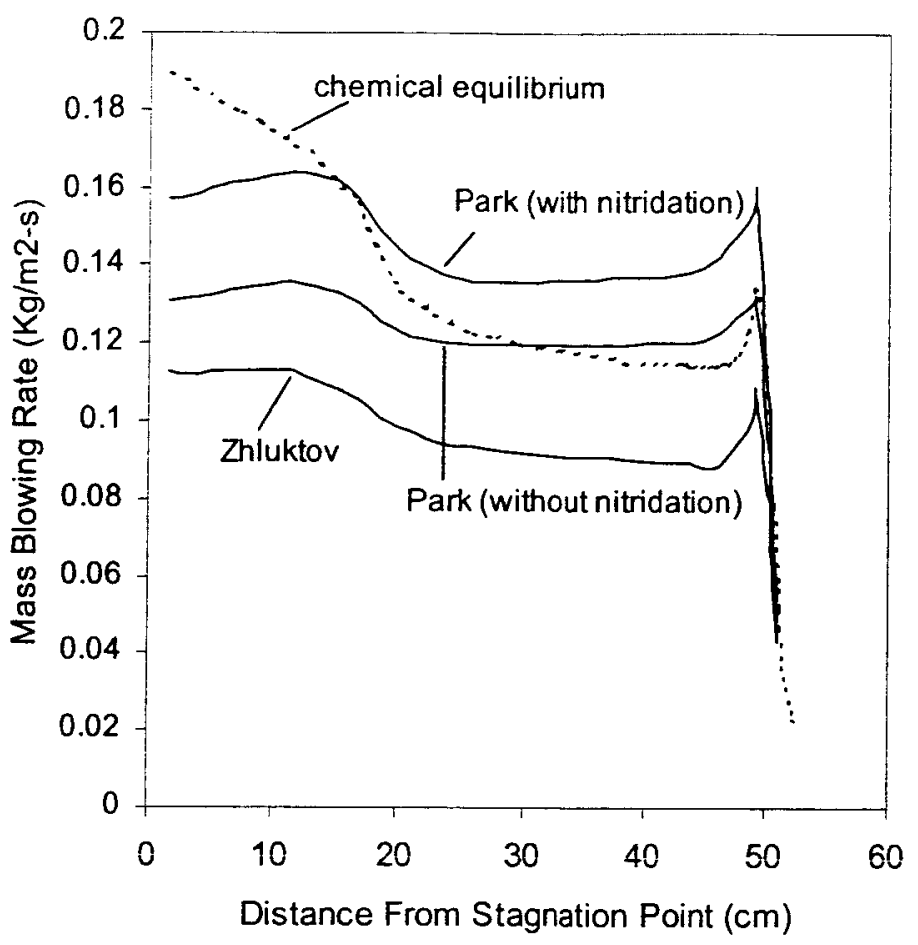

Figure 11: Predicted total mass blowing rate distributions for case 3

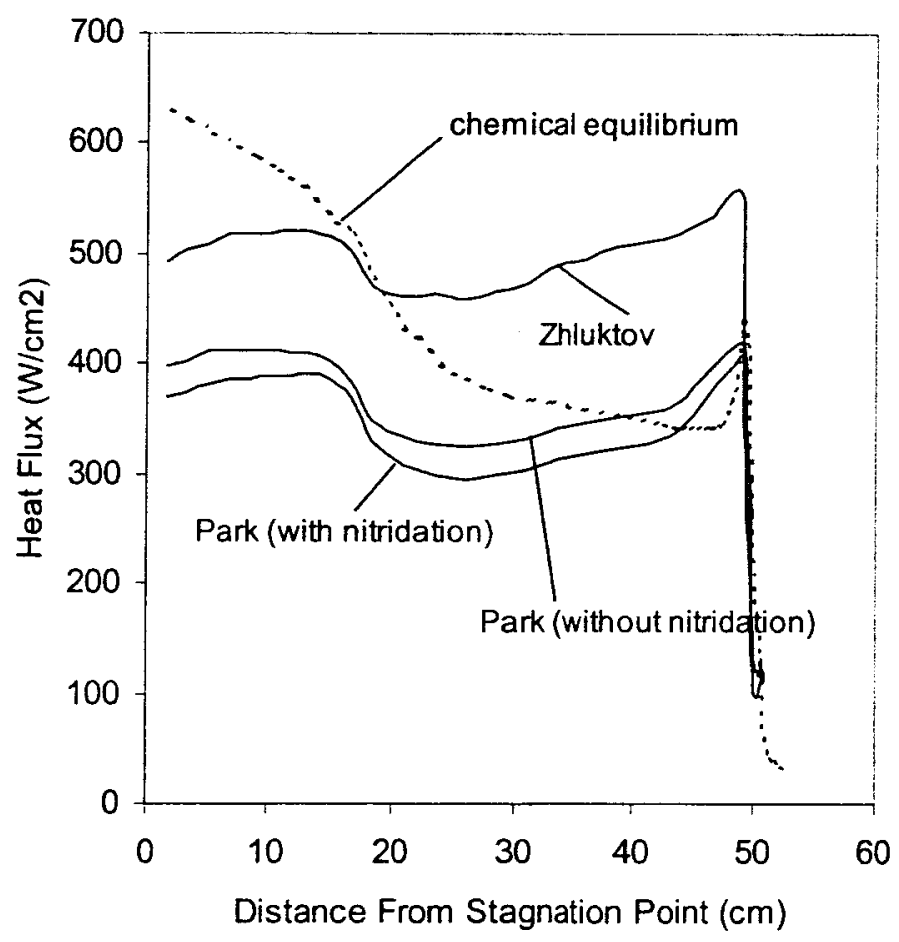

Figure 12: Comparison of convective heat flux predictions for case 3 . 